\title{
LA MUERTE Y SUS DISCURSOS EN LA ESPAÑA DEL ANTIGUO RÉGIMEN (1)
}

\author{
MARÍA JOSÉ DE LA PASCUA SÁNCHEZ \\ Universidad de Cádiz
}

Reflexionando sobre el título genérico que da nombre a estos cursos, y especialmente sobre las tres parcelas temáticas en las que se inscriben, se me ocurría que un tema tan amplio como la muerte y sus discursos debía situarse, para este efecto, bajo el objetivo analítico de la funcionalidad social del discurso sobre la muerte en la sociedad del Antiguo Régimen. Acostumbrados como estamos a una interpretación simple de los gestos, también de los que se articulan alrededor de la muerte, los identificamos con su significado más evidente o con el que ha permanecido como significado dominante en la memoria colectiva. Así, los gestos ante la muerte en la España católica de antaño, son sinónimo de religiosidad. A través de este esquema simplificado y mutilador nos privamos no sólo de múltiples lecturas, sino también muy probablemente de su lectura más calibrada, de aquélla menos evidente, más atmosférica, y por esta doble característica más eficaz en términos sociales. Por ello, más que atender a los significados doctrinales del ritual de la muerte, nos instalaremos en un plano distinto, preguntándonos por los servicios que presta una determinada imagen de la muerte a un . colectivo social en el momento histórico que estamos considerando.

En el ritual de la muerte podemos distinguir entre una funcionalidad antropológica -la ley universal que necesita hacer comprensible y significable una muerte cualquiera- y una funcionalidad histórica. Mientras que en la primera es posible observar gestos muy generalizados en el tiempo y en el espacio (duelo, búsqueda de un lugar para el descanso de los muertos, inmediatamente transformado en lugar sagrado, y memoria de los muertos, recuerdo éste invadido en ocasiones por el miedo al regreso de los difuntos), la funcionalidad histórica de la representación de la muerte es, como la propia palabra indica, variable y temporal. La muerte es resignificada constantemente y su representación utilizada con diversos fines, destacando, sin duda, el uso de su potencialidad pedagógica. La muerte es un magnífico motor y argumento de aprendizaje social y una eficaz arma disuasoria. Impuesta al hombre a través de su realidad como algo aparentemente ininteligible, ha sido con frecuencia trascendentalizada en un esfuerzo por encontrarle justificación dentro de un sistema religioso determinado. De esta forma, la muerte como la vida, han encontrado sentido como actuaciones positivas de las fuerzas divinas que, en el caso de la religión cristiana es un Dios que ha creado al hombre a su imagen y semejanza; un Dios suprema bondad y todopoder, al que el hombre ha traicionado con el pecado, y por cuya traición se ha hecho acreedor de un castigo. La muerte aparece así como una respuesta a la maldad del hombre. El 
pecado de origen vició, además, toda la vida del ser humano que no sólo es condenado a la mortalidad, sino también a una vida de trabajos y sufrimientos, a una «no vida».Ésta, no obstante, encauzada a través del respeto a los preceptos religiosos se positivizará, garantizando una sobrevida feliz y transformando a la muerte en un tránsito selectivo.

De todo ello se está derivando, obviamente, un modelo de comportamiento sociorreligioso que, enunciado de forma simple, podría resumirse en: una vida temporal llena de trabajos y peligros, separada de una verdadera vida por la muerte (juicio), o, como reza una proclama muy utilizada en la época «bien vivir para bien morir». Este modelo sufrirá variaciones a lo largo de siglos de cristianismo, pero alejémonos por un momento de estas matizaciones y permanezcamos junto al esquema descarnado a fin de preguntarnos si esta representación de la muerte es sólo un modelo de comportamiento religioso o tiene otras utilidades.

Conceptualizar la eternidad y luego traerla constantemente a la memoria ¿para qué?. En primer lugar para obtener consuelo. La garantía de un premio en otra vida poblada de felicidad tiene la virtud de convertir la muerte en un pasaje, en un tránsito esperanzado. Es ésta una respuesta casi de carácter antropológico, puesto que la resignificación de la muerte como puerta de paso hacia otra vida es frecuente en diversas culturas. Pero a esta faceta consoladora, hemos de unir la de relativizadora de la vida: todo lo bello, todo lo bueno, todo lo verdadero queda para el más allá, apareciendo este mundo como un desierto, ese yermo, según una expresión muy familiar en la época, que es preciso pasar para llegar a la tierra prometida. Esta segunda característica del sistema cristiano de representación de la muerte conduciría a una actitud quietista si el hombre de fe católica no tuviera que conquistar, a través de sus obras, la salvación. Ésta positivizará el mensaje condicionando conciencias y conductas y sometiendo los comportamientos a un programa de normalización y ortodoxia social que garantizará el mantenimiento del orden establecido.

El miedo a la muerte, o mejor el miedo inducido o generado por esta representación de la muerte, ha sido siempre una pieza básica en la pastoral de la Iglesia católica. No obstante, ha habido periodos en los que la manipulación de este miedo ha sido más intensa; con frecuencia en épocas de crisis en las que la ductilidad y manejabilidad del colectivo exigía un desarme psicológico previo a la enseñanza de una única salida: el orden. Así, y en esto coinciden historiadores como A. Tenenti, J. Le Goff o J. Delumeau, en el bajomedievo, época de cambios y desajustes importantes en la sociedad occidental, durante la cual el mensaje religioso, vehiculado a través de la predicación y de las artes plásticas, desarrollará un vasto programa de adaptación del hombre al pensamiento de la muerte. Así también en la época de la Contrarreforma en la que la reciedumbre de los tiempos demandaba recios controles en forma de advertencias comprensibles por su evidencia y fácilmente aceptables por su contundencia. Así, especialmente en el siglo XVI, crisol en el que se ensayará con éxito, por parte de los poderes públicos y religiosos, un buen número de 
recursos conductistas, según confirmó el prof. Maravall hace ya algunos años (2).

Aunque más adelante podremos detenermos en los discursos a través de los que una imagen de la muerte se divulgaba y vulgarizaba en la época, no resistimos la tentación de una guinda que, por su claridad programática nos permitirá avanzar por este argumento que acabamos de exponer sin necesidad de ejemplificar constantemente en los distintos mensajes. En el Catecismo generado por Trento para servicio de los curas párrocos, en su capítulo XII dedicado a la Eternidad, se habla de una de las claves complementarias de la representación de la muerte cristiana, la resurrección de los muertos, en estos términos. Después de definirla como «firmísimo fundamento de nuestra salud», se detiene en las «utilidades» tan «grandes y excelentes» que obtendrá el párroco de «trabajar este artículo». Entre ellas se destacan, aparte de la más evidente, a saber, el conocimiento de esta gran verdad que a muchos les fue vedado, «el poder consolar facilmente, asi á otros, como á nosotros mismos en la muerte de nuestros deudos y amigos... Asimismo en todos los demás trabajos y calamidades aliviará tambien sumamente nuestro dolor la consideración de la Resurreccion venidera» (3). Consuelo y relativización de los males de este mundo no eran beneficios de poca monta precisamente, pero los párrocos debían saber que esto de la muerte daba para más. El siguiente párrafo no tiene desperdicio:

«Finalmente será muy poderosa la meditación de este Artículo, para persuadir á los Fieles, que cuiden con la mayor diligencia de hacer una vida recta, pura y libre de toda mancha de pecado, porque si consideran, que aquellas inestimables riquezas que se siguen á la Resurrección, están aparejadas para ellos, facilmente se dejarán atraer al partido de la virtud y santidad. Y al contrario, no habrá cosa más poderosa para refrenar los apetitos del animo, y apartar á los hombres del pecado, que el hacer freqüente recuerdo de las penas y tormentos, con que serán castigados los malos, que en aquel ultimo dia resucitarán para el Juicio de su eterna condenación» (4).

El mecanismo conductivo está meridianamente claro. El móvil: persuadir; atraer/ refrenar, apartar. El medio uno de los resortes de mayor eficacia psicológica: el miedo. Un miedo suscitado, imaginado, sugerido por el recuerdo permanente de las penas y tormentos del infierno. Se podrá exponer de forma menos burda, - con la misma eficacia y una pluma más sabia desgranará el padre Nieremberg algunas consideraciones sobre la Eternidad en un clásico del género (5), pero el esquema es idéntico: la memoria de la muerte y su poder para tornar comportamientos y enderechar actitudes.

Sin embargo, una explicitación tan general y descarada de las utilidades de la memoria de la muerte si resulta conveniente en un manual para párrocos, no lo es con vistas a la instrucción de los fieles. El mensaje, imaginado y difundido 
como un mensaje de salvación, raras veces se presenta en su desnudez esquemática. Muy al contrario su aparente monolitismo se escapa a través de las múltiples posibilidades de adecuación que posee. Para aumentar su eficacia se acerca a la cotidianeidad y se individualiza, y también se estamentaliza, presentándose siempre como un programa de salvación a medida para cada situación social, para cada ocasión del año, para cada circunstancia de la vida. Aunque esta aparente diversificación no pueda llevarnos a engaño sobre posibles fracturas culturales -la sociedad española se encuentra empeñada en un esfuerzo de uniformización ortodoxa de la fe y las prácticas, según la consigna contrarreformista-, sí es importante señalarla porque tal y como era comunicada, fortalecía la ilusión de la jerarquía como algo natural, y del orden social como trasunto terrestre del orden divino.

La pastoral de la Iglesia, que hoy podemos seguir a través de una abundantísima literatura espiritual que estos siglos nos han legado en forma de Ejercicios de Perfección Cristiana, Áncoras de Salvación, Artes de Bien Morir, Reflexiones para cada día del Mes, etc., pero también en forma de Instrucciones de Confesores, Sumas de Casos de Conciencia, Sermones Fúnebres, y toda una extensa gama de obras de género normativo-disuasorio, predica que una buena muerte -una muerte seguida de premio- es siempre la consecuencia de un doble tipo de méritos. Los méritos acumulados a lo largo de la vida (merecimientos en el vivir) y los que se obtienen a la hora de la muerte (merecimientos en el morir). Aunque los designios de Dios son desconocidos y, por gracia divina, uno puede conseguir una buena muerte tras una vida descarriada, es frecuente -se encargarán de advertir los directores de conciencia- que una muerte feliz no sea más que la consecuencia de una vida buena. Por eso no hay mejor garantía de salvación que acumular buenas obras a lo largo de los años, con ello se merece una muerte santa. Además, ésta no se improvisa, se aprende ejercitándose para ella en el día a día hasta hacer de ese último momento, el único definitivo de nuestra existencia, el resultado de un Arte, el Arte de Bien Morir.

Pero este mensaje, de carácter aparentemente generalizante y democrático, que se condensa en la frase más repetida de toda la literatura espiritual de preparación de la muerte: Bien vivir para Bien morir, se ofrece, según apuntábamos, en forma de modelos de comportamiento adecuados a distintas situaciones vitales, que nos ayudan a profundizar sobre las derivaciones del mismo, ante esas significaciones menos evidentes pero más envolventes a las que aludíamos. Lo que sería el Manual para una vida perfecta es presentado en alternativas diversificadas para todos los estados y condiciones. Esta oferta de modelos de comportamientos masculinos y femeninos, variada como corresponde a la creciente complejización de la sociedad moderna, caracterizada a estas alturas como una sociedad pluriestamental, otorga a la literatura espiritual de los siglos XVI, XVII y XVIII un aire de «libros de estados», que es posible visualizar ya en los propios títulos de los libros (6), y contribuirá a la reproducción de un modelo social jerarquizado, constituyendo la parte más densa y bien trabada de un sistema de normas y prácticas que asegurará a los grupos dominantes el mantenimiento de su posición privilegiada. La 
salvación también era un asunto de cumplimiento de funciones, difundiéndose un estilo de vida/estilo de muerte que procuraba la sujeción no traumática al orden social vigente.

La evidente sintonía entre los modelos de comportamiento ofrecidos desde la Iglesia y desde los poderes públicos nace de la propia concepción de la organización social como reflejo del orden divino. La sociedad del Antiguo Régimen se imagina y se representa a sí misma como un todo jerarquizado y ordenado a imitación del orden del universo (7). Esta confluencia de intereses, este juego de alianzas temporales y celestes nos ayuda a entender la supervivencia en Occidente, durante ocho largos siglos, de ese imaginario trifuncional que vertebra la sociedad en dos grupos privilegiados y un tercer estado, y que traspasa estatus y funciones a través de la sangre. Permanencia, además, en creciente oposición a la realidad circundante que se impone díscola día trás otro, una realidad que nos habla de una sociedad cada vez más polarizada en función de la riqueza. Desde esta perspectiva, la funcionalidad del mensaje de salvación es claramente social, y dada la necesidad de reforzar los viejos esquemas de reparto de funciones ante los cambios que estaban operándose, claramente inmovilista, comportándose en este sentido como una ideología, en la que el orden simbólico colabora en la fijación de los principios de cierre y exclusión.

La funcionalidad social del discurso sobre la muerte se evidencia, especialmente, en tres ámbitos que se corresponden con tres formas de imaginar la muerte en su relación con el tiempo y en función de la distancia en la que se sitúa el observador respecto a ella. En un primer nivel, la muerte percibida como amenaza, generará una representación en la que la muerte se constituye como eficaz argumento normalizador de la existencia. En un segundo nivel, la muerte aparece como realidad presente (muerte propia o muerte de otro), y es reconducida a través de una liturgia, que tiene la virtualidad de imaginarla como algo controlable-explicable. Finalmente, en un tercer nivel o ámbito de distancia, la muerte como pasado nos permite observar la memoria de la muerte como parte sustancial de la memoria colectiva, vinculando el pasado al presente, y dotando así a la sociedad en su conjunto de una proyección de futuro. Dispongámonos a seguir el discurso a través de estos tres niveles.

La representación de la muerte como amenaza posee la virtud de relativizar este mundo, condicionándolo paralelamente al más allá. La salvación, la sobrevivencia, depende de la supeditación a las leyes divinas y humanas, y unas y otras indican que en este mundo jerarquizado cada cual tiene su función. Así lo expresa el beato Diego José de Cádiz, en la oración fúnebre que pronuncia en diciembre de 1788 con motivo de la muerte de los infantes Gabriel Antonio de Borbón y María Ana Victoria de Portugal.

"Y Dios es el que del mismo modo que ha criado diversos géneros de cosas, y en ellas diferentes especies con distintos individuos sin confusión ni desorden, así ordena en nosotros las diferentes clases, 
dispone las contrarias suertes que vemos, y establece destinos opuestos, y encontrados para el buen orden del universo» (8).

En este marco ordenado cada cual debe atender a las obligaciones de su propio estado, de forma que el conocimiento del ser «social» se convierte en una premisa fundamental. ¿Qué he de hacer para salvarme?, se pregunta el Dr. Joseph Guerrero de Ahumada ante el auditorio femenino del Colegio Real de Marchena: los medios «no son otros que vivir, andar y cumplir cada uno exactamente con las obligaciones de su estado al que Dios le ha llamado» (9). Nuestra salvación y la voluntad de Dios, que nos manda trabajar en tal estado, sigue diciendo el Dr. Guerrero, deben ser como los principios y causa de nuestra elección. Es preciso elegir el estado con deliberación, para realizarlo bien y no tener que arrepentirse. $Y$ es que a pesar de los cinco siglos transcurridos no estamos muy lejos de aquel comentario contenido en El Libro del caballero et del escudero: «si el home non cognosce su estado nunca lo sabrá guardar et si non lo guardare, todo su fecho traerá errado» (10). Idéntica advertencia nos hará el padre Nieremberg en el corazón del siglo XVII y con su habitual capacidad para hacer estremecer al lector:

«Porque si no cumplen con las obligaciones de su oficio, arderán en breve por una eternidad en los infiernos» (11).

Sabemos que la palabra «estado» (lat. status), se extiende a partir del siglo XIII con una doble connotación de función y permanencia. Covarrubias en su Tesoro de la Lengua castellana recoge tanto la acepción de ser como la de elección (12). El Diccionario de Autoridades repetirá este doble sentido como ser o condición en la que se nace, o aquella que se profesa (13). Ambas acepciones son recogidas también en la literatura espiritual de la época, presentándonos a una sociedad que, siguiendo la expresión braudeliana, se manifiesta como conjunto de conjuntos. Aparece el estado entendido en su función política, como expresión de una sociedad dividida en tres grupos (eclesiástico, noble y plebeyo). Pero también descubrimos la presencia de una sociedad teocrática, la que construye la Iglesia romana al dividir al conjunto de los fieles en dos estados: eclesiástico y secular. Aún más, la palabra estado aparecerá como sinónimo de función social dentro del marco de la sociedad patriarcal, y el estado para la mujer vendrá definido por su situación de dependencia de un hombre (doncella, casada, viuda).

Estas tres sociedades, estamental, teocrática y patriarcal, se superponen conformando un entramado de responsabilidades sociales que permitirán, dentro de una normativa común y generalizada, diversificar e individualizar los mensajes y, a partir de modelos y arquetipos, concretizar las funciones.

En el noble se alabará el cumplimiento de las obligaciones que corresponden a tan alto nacimiento: 
«nacer nobles, y no corresponder à las obligaciones de la nobleza, es mancharla, es degenerar, y envilecerse, disgustándose Dios de no ser servido de los que elevó para que le sirvieran los primeros, y diessen exemplo al resto de los Hombres» (14).

Ahora bien ¿cuáles son esas responsabilidades? En la línea de la función más tradicional, la militar, se glosan los valores innatos que se suponen a esta función como la valentía y la fidelidad. Así cuando se recuerda el naufragio de la balandra Bencejo frente a las costas portuguesas, la actuación de su comandante, el capitán D. Lorenzo de Mendoza y Moscoso se narra en estos términos:

«y viendo su ilustre comandante eran inútiles todos los recursos, y que precisamente perecían todos, cumplidos exactamente los cargos de capitán valeroso y hábil marinero, arroja la espada... y empuñando con christiana resolución un devoto crucifixo en un momento pasa de las disposiciones de un gran soldado, a las exortaciones de el Predicador más fervoroso. Si, hijos míos, decía este desgraciado joven con los ojos llenos de lágrimas, cumpliendo con la piedad y con las obligaciones más distinguidas de su nacimiento...: es preciso morir, porque así lo ha ordenado la providencia; pero moriremos sirviendo a nuestro Rey y Señor; y nuestro divino Redentor ha de premiar con su misericordia el cumplimiento de nuestra obligación» (15).

Sin embargo, conforme la nobleza pierda el monopolio de la función guerrera y desarrolle actividades relacionadas con el desempeño de funciones políticas, socioeconómicas y culturales, los rasgos de alabanza en los nobles variarán de plano, destacándose los valores de disponibilidad, buena crianza, amor a la instrucción y cultivo de las humanidades. Así se glosa, ya en el siglo XVIII, la figura del duque de Monte-Llano con motivo de sus exequias (16).

En el obispo se destacará, asimismo, el correcto desempeño de sus funciones profesionales y sociales. En el caso del obispo de Cádiz, Lorenzo Armengual, las reformas que llevó a cabo en su obispado, el impulso que dio al estudio de las letras, y el ejercicio del principal deber de un prelado: la caridad para con el rebaño (17). El mismo ejercicio de la caridad constante se destaca en el Elogio Fúnebre del también obispo fray Juan Baptista Cervera (18) en 1782, o un siglo antes en el sermón que se pronuncia con motivo de la muerte del prelado Antonio de Ibarra (19). En los religiosos, como en el caso del dominico fray Tomás Ripoll, su espíritu misionero, su incansable apostolado (20), y en aquellos que mueren con fama de santidad, además del ejercicio de su función, se subrayan aquellos perfiles de su vida y su muerte que aluden a esa santidad. Así sucede en el sermón pronunciado con motivo de la muerte del padre Chiesa donde se destaca, en primer lugar, una vida que transcurre «en el exacto cumplimiento de las leyes del respectivo propio estado, y la observancia más 
rígida de nuestra Regla Evangélica» (21). Pero no faltan en su biografía detalles de santidad según el arquetipo barroco: su desapego de los bienes materiales, su devoción al Ssmo. Sacramento y a la Virgen, sus ayunos y disciplinas y, sus continuos enfrentamientos con el demonio (22). Lo mismo sucede al trazar el perfil de otro religioso muerto en olor de santidad, el beato Diego José de Cádiz, misionero penitente, prodigio de humildad, pobre militante y casto en extremo. Apariciones y raptos completan una vida santa y elegida (23), amén de la señal inequívoca de santidad y general premonición sobre el momento de la propia muerte.

Un idéntico esquema se utiliza cuando se trata de recordar la trayectoria vital de los monarcas, ya se trate de Carlos II (24), Felipe V (25) o Luis I, quien en su breve reinado hizo gala de

«seria reflección de su obligación y encargo y para el más exacto cumplimiento de su oficio, assintio y condescendió gustoso, a que en su real Gavinete, se formasse una junta de ministros de calidad, rectitud, prudencia, letras y experiencia, para que le ayudassen a llevar la pesada carga del basto imperio...» (26).

El tercer estado aparece representado a través de aquellas funciones básicas, y las recomendaciones insisten igualmente sobre los posibles pecados de oficio. Al comerciante se le aconseja no dejarse embaucar por la ganancia fácil, especialmente se le advierte del peligro que corren los que se dedican a las finanzas. Así se le recomienda «que no haga cosa que no se pueda hazer con muy grande seguridad de conciencia, y que no se meta en opiniones de si peca o no peca, pudiendo granjear con su dinero cosa segura» (27). El referente de salvación para este oficio es la premisa agustiniana del trato que se redime si el objetivo del mismo es bueno, es decir, el sustento de la familia; premisa que la escolástica haría suya para eliminar el estigma que desde antiguo caía sobre la profesión mercantil. Al escribano se le advierte sobre el respeto a la ley y a la verdad en todas las escrituras que otorga (28), al trabajador que lo sea en los días de trabajo y que respete los festivos (29), y a los criados que obedezcan y no defrauden a sus amos $(30)$.

La oferta es, pues, variada, abarcando la multiplicidad de estados característica de la sociedad de estos siglos. En el Epistolario Espiritual del padre Juan de Jesús María, a través de 80 epístolas desfilan prelados, abadesas, religiosos, curas y monjas; también un eremita, un viudo, una beata, un virrey, un visionario, un enfermo, un moro, un maestro y un gobernador, detectándose una sobrerrepresentación del clero, especialmente del regular, y un sesgo claramente masculino. Perfil, por otra parte, típico de esta literatura espiritual (31).

La permanencia de esta imagen de «pecados funcionales» se difunde a través de una amplia gama de literatura religiosa entre la que no hay que olvidar las Instrucciones de confesores, por el efecto reproductor de estos mensajes en 
el confesionario, y se mantendrá durante buena parte del siglo XIX, haciendo depender la salvación del respeto al orden social. A los fieles se les propondrá un «examen de conciencia sobre los deberes del propio estado» (32), y a los confesores que preparen su ciencia teniendo en cuenta los lugares y a quienes han de confesar (33).

Pero en la sociedad de los siglos XVI, XVII y XVIII, como en la de los siglos anteriores y posteriores, una dicotomía básica de funciones construida en torno a la adscripción sexual, vertebra la red de papeles sociales a partir de una célula de socialización primordial: la familia. Durante estos siglos, tres discursos, el científico, el jurídico y el religioso, coincidirán en la adjudicación de una debilidad propia al sexo femenino que justifica la asignación a las mujeres de situaciones de subalternidad permanente. A ellas se les recomendará y exigirá obediencia, especialmente a todos los varones de su familia, y castidad, garantía de legitimación de la descendencia, indispensable en una sociedad ordenada por criterios de sangre y linaje. Los medios serán el enclaustramiento -en el convento o en el hogar- y el repliegue funcional en la familia. El proyecto colectivo de salvación para las mujeres queda supeditado al cumplimiento de sus obligaciones familiares. Así se advierte claramente en la Introducción a la vida devota de San Francisco de Sales, donde bajo el epígrafe Que la devoción conviene a toda suerte de estados y profesiones (34), puede leerse:

«Dios que en la creación del mundo mandó a las plantas que produjesen frutos cada una según su especie, manda a los cristianos, plantas vivas de su iglesia, que produzcan frutos de devoción cada uno en su calidad y estado. De diferentes maneras deben practicar la devoción, el caballero, el artesano, el criado, el príncipe, la viuda, la soltera y la casada; y se ha de acomodar también su ejercicio a las forzosas ocupaciones y obligaciones de cada uno».

Adviértase que el estado social de la mujer aparece identificado con su estado civil, de forma que sus obligaciones tienen que ver con las de una esposa, madre, hija o viuda. La mujer es, pues, receptora de un mensaje de salvación específico, y sus posibles pecados se medirán siempre con referencia a la funcionalidad que el orden patriarcal le asigna. También el hombre ha de responder a sus obligaciones familiares, la diferencia estará en que éstos tendrán funciones familiares y sociales, mientras que en ellas las funciones sociales serán las estrictamente familiares. En el directorio espiritual del jesuita J. Mach, muy popular a comienzos del XIX y que ya se ha citado, se explican los deberes del padre como los de control y dirección de todas las personas a su cargo (hijos, dependientes y criados), a los que debe dar ejemplo, vigilar y castigar. Parte de la vigilancia estriba en que mantenga «la separación debida entre ambos sexos», recomendándosele, además, la dirección espiritual de la familia a través del rezo del rosario en común diariamente. La mujer casada, por su parte, examinará si trata al marido con cariño y humildad, si cuida bien de los hijos y si presta excesiva atención a aquellas frivolidades que se consideran propias del sexo, a 
saber, gastar el dinero en vanidades, discutir con vecinas y parientes, perder el recato y la honestidad en el vestido y el proceder, o perder el tiempo en visitas y murmuraciones (35).

Pero quizá donde se perciban más claramente estos paradigmas de comportamiento sociorreligioso para uno y otro sexo es en los sermones fúnebres, en los que se ofrecen modelos de conducta a hombres y mujeres personificados en aquellos a quienes se está recordando. Es el caso del sermón que pronuncia fray Diego José de Cádiz, en 1788, con motivo de la muerte de los infantes Gabriel Antonio de Borbón y $\mathbf{M}^{\mathrm{a}}$ Ana Victoria de Portugal. Cuando se alaba a la infanta se dice que fue una mujer «humilde, callada, religiosa, pacífica, sufrida, misericordiosa y caritativa». Su única actividad, además de los deberes de la maternidad, parece radicar en dar limosnas -exclusiva función pública que se permitirá a las mujeres, tanto en el mundo católico como en el protestante-. En el príncipe, en cambio, se alaba el ser un hombre «cuerdo, sensato y juicioso», fiel cumplidor de sus deberes, que no descuidó su formación en latín, historia y física (36).

Junto a este mensaje de respeto al orden social, el argumento de consolación, tan abundante como el primero, reafirma esta funcionalidad social de la aceptación. La máxima es clara: cuanto más hayas recibido más se te exigirá; cuantas más penalidades pases en la tierra, más merecimientos en el cielo. Advertencias tales como que la alegría y el dolor caminan juntos en este mundo, que el camino del cielo es un camino de padecimientos, y que a sus grandes amigos da Dios grandes penas, se repiten con insistencia, regalándonos un mensaje a dos bandas que, utilizando dos de las cartas del Epistolario Espiritual (37) ya comentado, podríamos resumir en:

1. En este mundo no hay persona ni estado sin cruz.

2. Considera tus penas y enfermedades como un adelanto del Purgatorio y alégrate porque aquí padeciendo poco se merece mucho.

Esta última idea la hallamos repetida continuamente en las Artes de Morir y en la literatura espiritual de preparación de la muerte. $Y$ ello porque es precisamente en este segundo plano de reflexión que señalábamos, la muerte como realidad presente, donde el mecanismo consolador ante la inminente amenaza cobra más fuerza y es más necesario. Si la utilidad de la «representación de la muerte» como normalizadora de la existencia por miedo a un castigo futuro, es evidente, tambén lo es que ésta tiene que cumplir una misión esencial, a saber, ayudar al hombre/mujer a caminar hacia su encuentro sin desesperación. La desesperación, consecuencia terrible y frecuente ante la percepción de la proximidad del mal que acecha, es el enemigo más peligroso del cristiano a la hora de la muerte. Con la finalidad de hacerle frente, la literatura en torno a la muerte prevé dos soportes fundamentales. De un lado, el aprendizaje en el morir que, para que sea efetivo, se habrá realizado a lo largo de la vida en forma de ejercicios periódicos de preparación de la muerte (Ejercicios Espirituales). De otro, la ayuda de un especialista en el Arte de 
Morir, cuya misión será la de conducir al fiel desde el terror hasta la aceptación de una muerte cristiana.

En un Retiro Espiritual de finales del siglo XVII se nos explica cómo se muere bien. Lo primero es convencerse de la importancia de la preparación:

«ninguna -cosa- más dificultosa que la buena muerte: ninguna más irremediable que la mala muerte... Si se hubiese de morir dos veces, fuera menor la imprudencia de arriesgarse á morir una vez mal: se pudiera corregir el yerro, y hacer de una vez penitencia de la mala vida, y de la mala muerte pasada; pero se muere una vez sola, y la eternidad feliz o infeliz depende de esta vez sola» (38).

Convencidos ya de esta necesidad, conviene saber que una buena muerte es a menudo consecuencia de una buena vida, aunque puede ocurrir que el hombre consiga con una buena muerte borrar los pecados de toda una vida y viceversa, perder en el último momento lo merecido después de años de esfuerzo. La moraleja es bien sencilla, a saber, !vive santamente y aprende a morir santamente! La memoria de la muerte y el aprendizaje nos servirán, durante la vida, para no caer en el pecado, y en la hora de la muerte nos habrá facilitado el terrible tránsito.

El modo más eficaz de prepararse para una buena muerte es vivir bien, y esto para un cristiano es vivir en continua preparación para la muerte. Concretando más, se aprende a morir situándose mentalmente en ese momento con cierta frecuencia, una vez al mes, por ejemplo. Ese día nos comportaremos como si realmente fuese nuestro último día, haciendo examen de nuestros pecados, para a continuación hacer el firme propósito de no repetirlos (39). Además de este ejercicio mensual, es recomendable hacer uno intensivo una vez al año, dedicando todo un día entero a hacer lo que haríamos el día último de nuestra vida. Para ello, el día anterior se preparará todo a fin de no interrumpir el ejercicio, para el que se requiere gran tranquilidad y sosiego. La tarde víspera del día elegido, se hará una visita al Santísimo Sacramento, pidiéndole a Jesucristo la gracia suficiente para disponernos a una santa muerte, y a la Virgen; San Miguel Arcángel, los ángeles custodios, San José, el santo de nuestro nombre y el santo patrón, protección en aquella hora. Después, por espacio de media hora, se meditará sobre el uso que hemos hecho del tiempo, los medios y las gracias que hemos recibido para cuidar de nuestra salvación. El resto de la tarde se pasará en retiro y recogimiento, sin más quehacer ni pensamiento que un examen de conciencia. Por la noche, en caso de despertar, se renovarán estas reflexiones. Al día siguiente se iniciará propiamente el ejercicio dando las gracias a Dios, según nos despertamos, por permitimos prepararnos para morir. Después postrados ante un crucifijo, aceptaremos la muerte que Dios nos envía meditando sobre lo que acontece cuando se aproxima ésta. La meditación ha de ser «muy viva», considerando: El estado a que se reducirá nuestro cuerpo, el olvido que de nosotros harán deudos y parientes, la vanidad de un mundo 
deshecho por la muerte y el peligro que corremos de una mala muerte. Señalado el contenido de la meditación se propone, también, un escenario adecuado. Se recomienda la oscuridad para dar mayor intensidad a la meditación; y la proximidad de algunos objetos útiles en la reconstrucción del Memento Mori: una calavera, la luz de una candela, un crucifijo, el hábito con el que hemos de ser sepultados, etc. Después, se afrontará una confesión general, como si fuese la última, tras la que se recibirá la comunión a modo de Viático y se otorgará testamento. El resto del día ha de pasarse con recogimiento, leyendo algún libro espiritual que hable de la muerte «de los que se hallarán muchos muy al caso». Aunque en tal día debe uno privarse de conversación, puede ser recomendable la visita a un enfermo o a un moribundo, a fin de «ponernos más a los ojos lo que hemos de ser muy presto»; terminándose el día con una meditación sobre el juicio particular (40).

¿Qué efectos prácticos se derivan de este ejercicio de aprendizaje?. El fruto principal será el desapego de todo lo que precisamente se ha de dejar con la muerte, a saber, la vida o, como también se dice en la época, adquirir la ciencia de descarnarse. Otros frutos prácticos serán el aborrecimiento del pecado y la reforma de las costumbres. En cualquier caso, llegado el momento y a pesar de este aprendizaje, era conveniente la orientación de un especialista en el arte de morir, alguien capaz de ayudarnos durante la agonía para caminar desde el terror-con todas sus consecuencias imprevisibles y por tanto potencialmente alteradoras del orden- hasta la resignación. Este pasaje se realiza imaginando la muerte como el último paso del vivir temporal y el primero de la vida eterna o, también, como el paso del tiempo a la eternidad -definición de la muerte frecuente entre los autores religiosos de la época-, dotándola así de un sentido del que en una percepción objetivada carece. La funcionalidad social del ritual de la muerte a este nivel va desde la aceptación de la propia muerte: asunción del «voy a morir», facilitada con la preparación del testamento, pasando por la invitación a la familia para que se resigne a ella, mediante el ejemplo que ha de dar al moribundo de paz y sosiego, hasta la integración de la muerte en la vida social a través de los ritos de inhumación. Toda esta liturgia tiene la virtualidad de reconducir la muerte -realidad que se percibe impuesta desde fuera-, de socializarla y, a partir de una serie de prácticas normalizadas y conocidas, superarla, es decir aceptarla.

En este segundo nivel de representación de la muerte como realidad presente, podemos distinguir dos fases; una en las que el moribundo se prepara para morir -la agonía- y otra, posterior a la muerte, en la que el difunto es separado de la sociedad de los vivos. Ambas fases son objeto de reglamentación, si bien la primera da origen a una literatura específica y abundante, fijada ya desde el Medievo y que se conoce como Ars Moriendi. El objeto de esta literatura que pretende un aprendizaje del morir es, según hemos comentado, vencer la desesperación y transformarla en resignación, proporcionando al moribundo una serie de ritos a los que someterse. Estos ritos, programados secuencialmente como etapas sucesivas por las que ha de pasarse, tienen la cualidad de desviar la atención desde el fondo -he de morir- hasta la forma - 
cómo he de morir-. El objetivo que para el enfermo estaría en un primer momento en librarse de la muerte, es encauzado, mediante el miedo a morir mal, hacia cómo conseguir una buena muerte.

El género se fija tempranamente alrededor de un discurso que intenta hacer derivar la buena muerte de la buena vida, trascendiendo así un primer mensaje de los Ars Moriendi bajomedievales que acentuaban excesivamente el peso de los últimos momentos en el destino eterno. Se diversificará a lo largo del siglo XVII -época de su máxima difusión-, aunque bajo la fuerza de la impronta jesuítica, permaneciendo fiel a un esquema al que se someterán todos. La ciencia del bien morir se centra, de un lado, en la preparación del alma (alcanzar la paz con Dios a través de la confesión, el testamento, y la recepción de los Santos Sacramentos), y en un segundo momento en el aprovisionamiento de amuletos (cruz, cera, letanías, plegarias, jaculatorias, oraciones) y el abandono confiado en Dios y en la labor de los intercesores. El tratado de bien morir se perfila como un Manual de primeros auxilios que puede ser utilizado tanto personalmente como para ayudarnos unos a otros, de ahí su pequeño tamaño, para que pueda acompañarnos siempre (41).

El proceso de preparación final se desencadena con la enfermedad. Ésta es la embajadora de la muerte, la voz de Dios que nos llama y ante la que hay que responder con la debida disposición. Lo primero es llamar al sacerdote o al especialista, antes incluso que al médico, para que nos asesore sobre todos los pasos que han de darse. Un examen exhaustivo de conciencia, con un dolor verdadero de contrición, debe preceder a la confesión general «humilde, verdadera y entera» y al Viático (última comunión) (42). Es el momento de hacer testamento si no se ha hecho, o de validarlo si ya se otorgó -y ello porque las mandas piadosas hechas en pecado mortal no tienen utilidad espiritual-. El testamento es definido por Alvarado, Pedro de la Fuente y E. Nieremberg, en tres clásicos del género (43) como una protestación de justicia con que el hombre se apareja para dar a cada uno lo suyo. Todos los autores hacen hincapié en la necesidad de hacer testamento cuando se goza de buena salud y en los peligros de dejarlo para los últimos momentos; sin embargo, también se hacen eco de la costumbre de dilatario hasta que la enfermedad es grave; actitud que se ha constatado en los distintos trabajos realizados sobre testamentos, en los que el análisis del estado de salud en el momento de otorgarlos es concluyente en este sentido. Experto psicólogo, el Padre Nieremberg ofrece dos causas que fundamentan esta práctica testamentaria dilatada hasta los últimos momentos; que son según él, la esperanza de vivir, es decir, la dificultad que el ser humano tiene para asumir la propia muerte, y el apego a los bienes temporales (44). Ante esto recuerda que, como consecuencia de este error; muchos se quedan sin hacer testamento o lo hacen atropelladamente y sin la reflexión conveniente, por lo que quedan

«sus cosas entrincadas, expuestas a muchos pleitos, los suyos descontentos, cargadas sus conciencias y sus almas perdidas 0 , a mejor librar, condenadas a riguroso y largo purgatorio» (45). 
Mejor que ello: Piénsese que ha llegado la hora del juicio y haga testamento en reflexión consigo mismo, dando a cada uno lo que corresponde. Pague sus deudas, deje a sus herederos lo suyo, y si le sobra empléelo en casar huérfanas y otras obras de piedad. Deje toda vanidad y ostentación, sigue diciendo Nieremberg, y haga su testamento con piedad y justicia (46). Pero es el franciscano Pedro de la Fuente el que incluye un apéndice completísimo sobre cómo se ha de hacer testamento (47). Al objetivo, expresado ya, de evitar pleitos, el franciscano une una eficacia más, a saber, una vez se desprende uno de todos los bienes materiales es mucho más fácil aceptar la muerte:

«De estos impedimentos suele aliviar el buen testamento: que el que se determina a dar a cada uno lo que fuere suyo..., fácilmente se descarnará de las amistades y naturales passiones, sujetándolas a la razón, confortarse ha de la ausencia de la mujer, de los hijos y de los amigos» (48).

Para este proceso P. de la Fuente utiliza el verbo descarnar, que describe el significado de la muerte dentro del discurso cristiano. El testamento ayuda a descarnarse, esto es, a abandonar los bienes, mandar el cuerpo a la tierra y entregar el alma a Dios. En cuanto a qué tipo de testamento conviene hacer, también en esta obra se hacen sugerencias muy suculentas. Así, se recomienda, en determinadas circunstancias y a las mujeres casadas, el testamento cerrado,

«porque libremente puedan hazer de sus bienes lo que más convenga a sus conciencias, sin tener respeto a sus maridos: porque si no las heredassen, si de la enfermedad saliessen, las tratarían después mui mal porque no les mandaron sus haziendas o parte de ellas» (49).

Aunque en el tema de la práctica religiosa en la literatura espiritual se concede habitualmente a la mujer libertad suficiente, incluso por encima de la obediencia debida al marido, semejante alegato contra el respeto al cabeza de familia resulta un tanto desconcertante en un discurso eclesiástico caracterizado por una tradicional misoginia. La experiencia debía estar dictando al franciscano estas recomendaciones que, por otra parte, no cesan aquí, pues lo mismo que advierte de la conveniencia del testamento cerrado, recuerda a los confesores que avisen a los maridos de la obligación que tienen de declarar las dotes de sus esposas en sus testamentos (50). Sin duda conocía los abusos a los que daba lugar la administración por parte del marido de los bienes parafernales. Otras sugerencias se enmarcan dentro de una general desconfianza hacia albaceas y familiares, instándose a que las decisiones importantes sobre los bienes las tome el interesado, cuidando de hacer obras de misericordia, y no de «vanas memorias, ni que queden hazendados y ricos sus herederos, y más quando no son los hijos» (51). Obviamente, este aviso del padre Nieremberg no debe entenderse sobre lo que legítimamente pertenece, pues en todas las mandas y 
legados el deber de justicia prima sobre el de gracia (52). De lo que se puede disponer libremente -el quinto en presencia de herederos forzosos-, se debe legar en favor del alma y de los pobres. En cuanto a la superioridad de unas mandas sobre otras, el padre Alvarado es más explícito, enumerando las diferentes misas del alma y de difuntos que gozan del beneficio de indulgencias, y, como otros especialistas del género, se pregunta si es mejor la fundación de memorias y capellanías que la celebración de misas en el tiempo corto. Se decide, lo mismo que de la Fuente, por las primeras, pero advirtiendo que la bondad del gesto queda supeditada a su intención y a las circunstancias: «en alguna ocasión, escribe-; puede que las obras temporales sean más gratas a Dios que las perpetuas» (53).

Después del testamento, el moribundo debe recibir la extremaunción, sacramento instituido por Cristo, con el doble efecto de curar el cuerpo -si así conviene, según los designios de Dios-, y fortalecer el alma preparándola para el trance de la muerte y de la desesperación, simbolizada esta última en los tratados de Bien Morir como un combate con el demonio. Además de la Sancta Unción, el enfermo debe disponerse para la agonía con actos de fe, esperanza y caridad, mediante oraciones. Éstas, presentadas con profusión y variedad en todas las Artes -con la recomendación unánime de que sean breves para no agotar al enfermo-, junto con la cruz y una candela que simboliza la fe, serán las armas de las que disponga en los últimos momentos de la agonía.

Las Artes de Morir nada dicen de la sepultura ni del funeral. No parece sino que el moribundo es sólo un alma y el destino del cuerpo apenas merece comentario alguno (54). Aparte de una breve sugerencia a la inutilidad de unos funerales pomposos (55), el silencio puede interpretarse como una concesión a la sociedad. Durante la agonía, los únicos protagonistas eran el moribundo y el sacerdote que le ayuda a morir, pues aun en el caso de admitirse la presencia de familiares y amigos, ésta tiene lugar en los últimos momentos, cuando el moribundo está ya preparado para morir y ha aceptado plenamente su situación. Su aparición, por otra parte, es la de simples comparsas y como meros espectadores de una muerte asumida y edificante. Las primeras horas que siguen a la muerte son las únicas controladas por la familia; tiempo de preparación del cadáver y del duelo; tiempo controlado por las mujeres de la casa que confeccionan los lutos, preparan el chocolate y los dulces para la larga vela, y cursan recados e invitaciones para el convite. Son horas de intensa actividad entre bastidores, que nos ponen en relación con lo más prosaico y humano de la muerte, pero que apenas queda reflejada en los discursos. Aparte de alguna advertencia a lo inconveniente de unos duelos excesivos, común a la pastoral y a las leyes civiles, y el aviso de una minoría de testadores para que no se quiten los muebles, cuadros, y colgaduras, ni se hagan otros gestos exagerados e injustificados, un intenso mutismo envuelve las horas siguientes al óbito. Algunas referencias en la literatura de viajes y costumbrista, y sobre todo las cuentas del quinto de los inventarios post-mortem, permiten al historiador seguir esos momentos reservados a la familia y que parecen quedar fuera de la «normalización» por parte de una pastoral que se muestra discreta. Al fin el acto 
más importante que en esos momentos está teniendo lugar, desde el punto de vista de la Iglesia, -el juicio particular al que es sometida el alma-, escapa por completo a su control. Es un tiempo vacío, en el que la muerte se repliega en el espacio privado; un tiempo intermedio entre dos fases socialmente muy importantes: la agonía y el entierro. En esta última, la muerte saldrá al espacio público, convirtiéndose en un espectáculo participativo y colectivo. Espacio de afirmación social en el que el lenguaje a utilizar estará codificado, cargado de guiños de consolación sobre un soporte de respeto a las jerarquías. Pero aún más importante, en este tercer momento, la sociedad se apropia de la muerte, y sometiéndola a su propio lenguaje la hace suya. Algo que se imponía desde afuera, como una fuerza extraña e indomable, se transforma, en el espacio social en el que se situará al muerto, en un acontecimiento social más, propicio para el fortalecimiento de vínculos y solidaridades horizontales y verticales, y lugar de la reproducción del sistema a través de la divulgación de los «tics» comunes y la formación de la memoria colectiva. Al situarnos en este plano, el de la muerte socializada, el objeto de estudio deja de ser ya el muerto, cualquier muerto, para pasar a ser el grupo.

El modelo de exequias que suministraba el Ritual Romano era muy sencillo. A las 24 horas de la muerte, como mínimo, se efectuaba el entierro para el que:

«convocados el clero y ministros que deven asistir, tocadas las campanas según la costumbre, se vestirá el párroco de sobrepelliz y estola negra o capa pluvial del mismo color, y con los demás asistentes desde la yglesia irá a la casa del difunto, llevando un clérigo la cruz y otro el agua bendita. Allí se echa ésta al cadáver, se encienden velas de cera, se dicen antífonas y salmos y en forma de procesión se conducen a la Yglesia, poniendo en medio de ella el féretro y diciéndole el oficio de difuntos» (56).

Además de esta sencilla ceremonia, el Ritual Romano sólo consideraba preceptiva, antes de la sepultura, y ello siempre que fuera posible, la misa del alma con el cuerpo presente.

Sin embargo, este modelo será sólo un armazón sobre el que una creciente complejización de las exequias se sostendrá. Los curas párrocos estaban en posesión del sagrado derecho y deber de «levantar» con la cruz parroquial el cadáver, y acompañar a aquel con quien había compartido sus trabajos y su fe, «con salmos y paramentos lúgubres». Pero los funerales eran algo más, eran pompa funeral o aparato, es decir, exhibición pública del poder de una casa y su titular, refrendo de posición social, y eran también, casi la única fuente de ingresos de un clero parroquial marginado frecuentemente del reparto decimal, y que tenía «en las ofrendas fúnebres la parte más considerable de sus obvenciones y casi el único medio de subsistencia» (57). Estas cualidades añadidas, contribuyeron a alejar las exequias de este esquema simple comentado, y a hacerlas derivar hacia la imagen de las mismas como espectáculo 
de afirmación social. Numerosas fuentes provenientes del clero constatan esta proclividad de los fieles a manifestar en los funerales la mayor pompa posible, y es que los servicios públicos por los muertos se hacen:

«pero por lo común se hacen más para honrar las tristes reliquias del difunto que para aliviar su alma. Se hacen, cuyo fausto, caso no sirve dice San Agustín-, sino para el consuelo de los que sobreviven a los difuntos. Se hacen, y según lo que vemos, no para agregar sus votos a los de los ministros del altar, sino para ostentar una vana pompa, allí mismo donde ven sonrojada y abatida la soberbia del hombre» (58).

Ellos, los curas, lo único que hacen, según se disculpan, es cobrar un pequeño tributo sobre ese lujo que los fieles desean. Sin embargo, no era tan sencillo. La confusión sobre el primitivo significado religioso de muchos de los componentes de las exequias se había perdido y el mismo clero había contribuido a ello.

Uno de los elementos indispensables en el cortejo fúnebre, según se ha visto, era el clero; en rigor, el único indispensable era el cura de la parroquia a la que pertenecía el difunto, sin embargo, el «convite» a todo el clero parroquial, y por extensión a las comunidades de mendicantes radicadas en la ciudad se hizo frecuente entre quienes podían pagarlo: El original papel «intercesor» de los integrantes religiosos del cortejo, cuya misión era rogar por el difunto, va oscureciéndose frente a otras funcionalidades, a saber, comunicar a los demás a partir del número de acompañantes la importancia del difunto y su casa. $Y$ en este juego de representaciones quedarán prendidos también los miembros del estamento eclesiástico. Cuando los curas párrocos de Cádiz tienen que contestar a la acusación que los fieles les han hecho de no acudir a los entierros, contestan que cuando no acuden -porque están enfermos o tienen otras obligacionesmandan a un capellán en su lugar, «que llenan el hueco, en lo que no queda defraudada la parte en el número de individuos de asistencia» (59). Es decir, también para el clero la importancia del acompañamiento venía dada por lo que representaban «socialmente» unas exequias numerosas, y no por el carácter sacerdotal de los acompañantes y, por tanto, de refuerzo de plegarias.

El carácter jerarquizado de las exequias no se detiene aquí, en el número de clérigos que acompañan al difunto, y que lógicamente varía en proporción al arancel de las mismas, sino que va reforzándose a través de la escasez/ abundancia de cada uno de los elementos que participan en ellas: el doble de campanas, la música, las hachas y cirios, los pobres mendigos, las cofradías... Las alusiones en los testamentos a un entierro «conforme a mi estado», o bien las lamentaciones por no poderlo realizar como realmente quisiera «sin pompa», debido a las obligaciones propias del estado social (60), hacen explícita esta conciencia colectiva acerca de una procesión fúnebre que «petrifica» en la última aparición pública, y a partir de ella en la memoria del grupo, las señas de identidad sociales del difunto. 
La exhibición pública de las pertenencias sociales no vendrán sólo de la mano de la aparición de elementos propios (hábito de la orden militar a la que se pertenece, vestiduras sacerdotales, escudos de armas en la sepultura...) o de cortejos resplandecientes, sino también de la mano de una cierta ostentación de la humildad y la renuncia. Al compás de la extensión de unas exequias barrocas por un universo social cada vez más amplio, se abre paso, entre los grupos de notables, una rara, privativa y decidida voluntad de humildad que, en el Toledo de los siglos XVI y XVIII, se manifestaba en la celebración de entierros nocturnos, sin apenas acompañamiento (61), y que se recoge en los testamentos españoles de los siglos XVII y XVIII (entre los miembros del Consejo de Castilla, en la Barcelona del Barroco, en el Cádiz de los siglos XVII y XVIII, o en la Córdoba finisecular (62). Sin embargo, los cambios no se anticipan, no al menos de forma positiva, en estos gestos que sí, en cambio, nos hablan de un deterioro de la práctica y de su pérdida de valor, como signo de prestigio social. En el momento en que el gesto de un cortejo excesivo deje de ser privativo de una élite, dejará de ser también un arquetipo al que acercarse o que imitar por parte de los grupos aspirantes. Los cambios, en sentido positivo, más bien vendrán implícitos en aquellos que empiezan a perder interés por cuidar sus exequias, y en la paralela pérdida del carácter religioso del cortejo y la sustitución de elementos simbólicos en el mismo por otros que refuerzan la representación familiar y otro tipo de solidaridades terrenas (63). Pero dejemos los cambios y la caída de las exequias barrocas, porque nuestro interés hoy se centra precisamente en la representación de la muerte en el Antiguo Régimen.

Las señas de identidad sociales que vemos en la conducción del cadáver a su última morada, se prolongarán, una vez el muerto ha desaparecido de la vista de todos, permitiéndonos situarnos propiamente en ese tercer nivel analítico de la Memoria de la Muerte. Ésta que, para la Iglesia, se inscribe en la doble perspectiva del «Acuérdate de tu muerte», por un lado y «ruega por los que te han precedido» por otro, posee una función básica para el hombre que es evitar el olvido. Así la memoria de la muerte será el intento de construcción de una memoria de sí mismo, en la que la angustia por abandonar el ser y penetrar en la nada domina los hábitos y gestos de cara a la posteridad. La pastoral había convertido el miedo natural a la desaparición en un miedo inducido, en un miedo al olvido, convirtiendo éste en una de las consecuencias lógicas de la muerte. Tomás de Kempis, en una de las versiones del más famoso libro de espiritualidad moderno, De la Imitación de Cristo, de mediados del XV, lo había advertido:

«¿Quien se acordará de ti despuẻs de la muerte? ¿Quién rogará por ti? Haz, haz ahora, amado mío, todo el bien que puedas, porque no sabes cuándo morirás, ni tampoco qué será de ti después de la muerte» (64).

Un anuncio semejante hacía, a comienzos del XVII, Francisco de Sales en su Introducción a la vida devota: 
«Considera la prisa que se darán para echar de allí tu cuerpo, y sepultarte en la tierra; y que hecho ésto, el mundo no volverá a pensar en tí, ni se acordará de tí,'así como tú no has pensado en los otros» (65).

Más terrible es la forma que adopta un aviso semejante por parte del jesuita padre Rosignoli, a comienzos del XIX:

«Bien sabemos qué suerte le ha de tocar al cuerpo; quedar allí pálido, feo, abominable, bastante a poner horror con el semblante, á inficcionar el aire con su pestilencial hedor, de suerte que todos huirán, habiendo apenas quien se atreva a cerrarle los ojos espantables. Los amigos más queridos serán' los primeros a volverte las espaldas, no teniendo aliento para estar con él sólo aún una noche. Los parientes más cercanos procurarán cuanto antes echarlo de casa, no pudiendo sufrir más aquel cadáver que les llena de profunda melancolía. Se buscará el lienzo más viejo y despreciable para envolver al que sólo permitía le tocasen delgadísimas holandas...» (66).

El lugar común del olvido sirvió de hilo conductor a la Iglesia para advertir a los fieles de la importancia de hacer de la vida un testamento práctico (acumulando buenas obras durante la misma) frente a los testamentos teóricos hechos con poco tiempo y la premura de una muerte próxima, y en los que era preciso dejar los propios encargos en manos de otros, que no siempre tenían voluntad suficiente para cumplir con las mandas. No obstante, a pesar de estas desconfianzas y sospechas vertidas sobre albaceas y poderhabientes en la literatura espiritual de aviso, los testamentos se harán pocas horas antes de morir, y su contenido no lleva precisamente a pensar que su dilación se debe a la realización durante la vida de mandas, legados y sufragios. Sólo excepcionalmente el testador recuerda que dice pocas misas porque ya las ha mandado decir en vida, o que durante años se ha encargado de hacer limosnas e ir cumpliendo con legados piadosos; la mayoría de las fundaciones se harán, por otra parte, a través de testamento y no por documento «inter vivos». Es humanamente comprensible que los deseos de enmienda se enciendan con la proximidad de la muerte y que sea entonces cuando veamos concretizarse en gestos una cierta urgencia de salvación. Misas, en el corto y largo plazo, aniversarios, fiestas, limosnas y otras obras piadosas se amontonan en los testamentos barrocos, y sus cantidades y ritmos de su evolución y presencia, estudiados con exhaustividad, han sido interpretados en clave religiosa. Pero ¿es esta memoria de la muerte sólo una memoria de la salvación?. En el Diccionario Apostólico, citado más arriba, se aludía a un comentario de San Agustín referido a que todas estas cosas se hacen más por consuelo de los que sobreviven que por el alma de los que fallecieron y creemos que no es esta una percepción insignificante. A través de esta memoria de la muerte, el grupo restaña sus heridas, reutiliza estos materiales de despojo para socializar una realidad -la muerte- ante la que en principio se encuentra inerme. Como los 
restos físicos de los muertos se convierten en un «humus» fertilizante de la tierra y de la nueva vida, así el dolor, la pérdida, o el enfrentamiento a la nada, revertirán dando consistencia a la memoria colectiva, memoria que también incluye a los muertos. Cómo se ensambla el individuo en esta formulación colectiva, y cómo canaliza sus disidencias es otro tema. Hoy nos hemos reunido para hablar de códigos. Baste entonces.

\section{NOTAS.}

(1) Este artículo fue escrito en el año 1994 con vistas a la participación en un curso sobre «Letras, códigos y honores en la España del Antiguo Régimen». Problemas de última hora impidieron mi presencia en el curso y lo dejaron inédito. Hoy he querido recuperar el texto en memoria de nuestro querido amigo y compañero, el prof. D. José Luis Millán Chivite.

(2) J.A. MARAVALL, La cultura del Barroco, Madrid, Ariel, 1975, pp. 153 y ss.

(3) Catecismo Romano: Compuesto por Decreto del Sagrado Concilio Tridentino para los Párrocos de toda la Iglesia (Publicado por Pío Ven 1566). Manejamos la edición que fue realizada según la traducción que del latín al castellano hizo Lorenzo Agustín de Manterola, en Pamplona: Oficina de Benito Cosculluela y Josef Longás, 1780, dos tomos. Tomo I, p. 121 y 132.

(4) Tbídem, p. 132.

(5) El jesuita Juan Eusebio Nieremberg en su Diferencia entre lo temporal y lo eterno, publicado en Madrid en 1640, insiste en la importancia de «hacer vivo concepto de la eternidad» y «tener continua su memoria» para que la vida sea «más fuerte y más fecunda de santas obras». Utilizamos la edición de Madrid: Apostolado de la prensa, 1942, pp. 14-16.

(6) Epistolario Espiritual para personas de diferentes estados (Fray Juan de JESUS MARIA, Uclés, 1624); Tesoro de Confessores y perla de conciencia para todos los estados (J. DAZA Y BERRIO, Madrid, 1648) o el mucho más explícito Hierarchia celestial y terrena y símbolo de los nueve estados de la Iglesia militante con los nueve choros de Angeles de la Triunphante (J. de SADNA, Cuenca, 1603), cuyo título nos sugiere que sólo el Purgatorio, dominio de la Iglesia Sufriente, estaba libre de jerarquías estamentales.

(7) La noción de orden aplicada a las categorías sociales estamentales implicaba, como ha puesto de manifiesto G. Duby, desde su origen, los conceptos de jerarquía e inmutabilidad (Les trois ordres ou l' imaginaire du féodalisme. Paris: Gallimard, 1978, p. 90).

(8) Sermón Fúnebre, teológico-histórico-moral que en las solemnes exequias celebradas en el día 23 de diciembre de 1788 por el ilustrísimo, más antiguo y 
Real Cuerpo de la Maestranza de la mui noble y mui leal ciudad de Ronda...por el alma de su defunto Hermano Mayor el Serenísimo Sr. D. Gabriel Antonio de Borbón, infante de Castilla, y de la serenísima Sra. Dña. María Ana Victoria, infanta de Portugal y de Castilla, su fidelísima y dignísima esposa, predicó....Ecija: Imp. Benito Daza (s.a.), p. 4.

(9) Carta instructiva y edificante que el cura del Colegio Real de niñas educandas de la villa de Marchena, dirige a su comunidad con el motivo de la muerte de la hermana Antonia. Marchena: 1799, p. 15.

(10) Cit. por J.A. MARAVALL, «La sociedad estamental castellana y la obra de don Juan Manuel», Cuadernos Hispanoamericanos, 201 (1966), p. 457.

(11) J.E. NIEREMBERG, Diferencia entre lo temporal y lo eterno, op. cit., p. 17.

(12) Tesoro de la lengua castellana o española (ed. 1611). Barcelona: Alta Fulla, 1987.

(13) Diccionario de Autoridades (ed. 1737). Madrid: Gredos, 1969.

(14) Josep CAYO GRANDE, Oración fúnebre que en las exequias que celebró por el Excelentísimo Sr. Duque de Monte-LLano el Venerable clero de la ciudad de Sanlúcar de Barrameda...el 23 de julio de 1765, Cádiz, 1765, fol. 1.1.

(15) Juan LOPEZ DE HERRERA, Sermón pronunciado en el convento de Santo Domingo por las almas que perecieron en el naufragio del navio del Rey San Pedro de Alcántara y de la Balandra Bencejo en las costas de Peniche, reino de Portugal. Cádiz, 1787, pp. 42-44.

(16) Por estas fechas -1765-, la familia es un valor en alza y así se reconoce en el caso del duque de Monte-Llano, lo mismo que su permanente disposición para prestar servicios a Fernando VI, sus cualidades de buen político, y su disposición al cultivo de la Gramática y la Filosofía. J. CAYO GRANDE, op. cit., p. 14-18.

(17) Pedro Francisco CALDERON, Funeral Parenthacion en las honras que por muerte del Excmo. Sr. D. Lorenzo Armengual de la Mota, del Consejo de Estado de Su Majestad, Presidente en el de Real Hacienda, su Capellan Mayor y Vicario General del Occeano, dignissimo obispo de Cádiz, celebró su Ilustrissimo Cabildo. Sevilla, Imp. de la Viuda de Francisco Leefdael (1730).

(18) N. MADERA Y MORA, Elogio fúnebre que en las solemnes exequias que celebró la Hermandad de la Santa Caridad de Cádiz en su Iglesia Hospicio el 17 de abril de 1782, por el alma del Ilustrísimo Sr. Dn. Fr. Juan Baptista Servera, obispo de esta Ciudad. Cádiz: Imp. D. Juan Ximenez Carreño, 1782. 
(19) A. ROXAS Y ANGULO, Sermón que en las exequias que la Sta. Iglesia Catedral de Cádiz celebró a la memoria de su dignísimo prelado el Ilustrísimo y Reverendísimo D. Antonio de Ibarra. Cádiz: Imp. Cristobal de Requena, 1692.

(20) Ignacio DUEÑAS, Fünebre oración que en las solemnes exequias por el Rmo. Padre Maestro Fr. Thomás Ripoll...dixo en el Convento del Ssmo. Rosario y Sto. Domingo de la ciudad de Cádiz el día 29 de noviembre de 1747. Cádiz, 1747.

(21) P. DE LA TORRE, Sermón fünebre que en las sumptuosas honras ofrecidas en el Convento de N.S.P.S. Francisco de la ciudad de Cádiz por la devota y noble Esclavitud de la Corona y Sto. Rosario de María Ssma. de los Remedios sita en el dicho Convento, a la respetable y santa memoria del Venerable Padre Fr. Juan Baptista Chiesa, Cádiz, 1766.

(22) Ibídem.

(23) Antonio HARDALES, Oración fúnebre que en las solemnes exequias a la honrosa memoria del siervo de Dios e insigne misionero Fray Diego Josef de Cádiz predicó....en Antequera, en 1801. Cádiz: Imp. Manuel Comes, 1801.

(24) F. DE AGUILAR Y ARAGON, Oración fúnebre en las reales exequias que celebró a el Rey Nr. Sr. D. Carlos II de gloriosa memoria la Real Armada Española. Cádiz, 1700.

(25) Geronymo I. CABERO, Oración Fúnebre que en las reales magníficas exequias que la muy antigua, muy noble y muy leal ciudad de Cádiz, dedicó en su Santas Iglesia Catedral a la piadosa memoria del Sr. D. Phelipe V, Rey de las Españas. Cádiz, 1747.

(26) F. CEPEDA Y GUERRERO, Reales Exequias, sentidos afectos, con que la antiquíssima, muy noble y muy leal ciudad de Cádiz, lamentó el fatal golpe de la temprana muerte del Rey Nuestro Sr. D. Luis I. Cádiz, 1724.

(27) P.F. Iuan DE JESUS MARIA, Epistolario espiritual para personas de diferentes estados. Uclés, Imp. Domingo de la Iglesia, 1624, fols. 680-683.

(28) Ibídem, p. 462.

(29) J. MACH, Ancora de salvación o devocionario que suministra a los fieles copiosos medios para caminar a la perfección y a los párrocos abundantes recursos para santificar la parroquia. Barcelona: Imp. Francisco Rosal, 1882, p. 131.

(30) Ibídem. 
(31) L.C. ALVAREZ SANTALO, «El libro de devoción como modelado y modelador de la conducta social: el Luz a los vivos de Palafox (1668)», Trocadero. Revista de Historia Moderna y Contemporánea, 1 (1989), pp. 1415.

(32) J. MACH, op. cit., pp. 121-131.

(33) «y assi los que se apruevan para Sevilla, donde ay tantos tratos, contratos y variedad de pecados y dificultades en ellos, ha de saber más que si se aprovara sólo para un lugar o para gente rústica, donde rara vez se ofrecen casos difíciles», Antonio de QUINTANADUEÑAS, Breve instrucción de ordenantes. Compendio de las cosas que deven guardar y saber en sus órdenes y se les preguntan en los exámenes...con un apendix del Examen de Confessores y Predicadores. Madrid: Imp. Melchor Sánchez, 1661, p. 383.

(34) Ed. original de 1609. En esta ocasión manejamos la ed. de Paris: L. Hachette, 1866, p. 38.

(35) Ancora de salvación...op. cit., pp. 126-131.

(36) Sermón Fúnebre teológico-histórico-moral..., op. cit., I y II parte.

(37) Op. cit., Epístolas XI, III y IV.

(38) Retiro Espiritual para un día de cada mes muy útil para la reforma de las costumbres, y para disponerse con una santa vida para una buena muerte. Trad. del francés al castellano por Enrique de la Cruz. Madrid: Imprenta de Pedro Marín, 1788, p. 118. Esta obra fue escrita por un jesuita francés del que desconocemos su nombre, así como la fecha de publicación -probablemente finales del XVII-. Una primera traducción de la misma está fechada en Milán, en 1704.

(39) El examen considerará «el descuido en las obligaciones de su estado propio...los sacramentos que se han frequentado sin fruto...las gracias, los medios de perfección que hemos hecho inútiles...». Conviene, asimismo, hacer reflexión sobre los negocios temporales y reglarlos de suerte que no nos inquieten...en fin, «se debe procurar hallarse al fin de este día en aquel estado mismo en que quisiréramos hallarnos en el último punto de la vida». Ibidem, op. cit., pp. 131-134.

(40) Tbídem, pp. 136-143.

(41) Así se nos dice en uno de los clásicos del arte de Bien Morir, condensando la filosofía católica de preparación de la muerte: el vivir bien es la principal regla para morir bien, pero hay otras reglas importantes para este paso, «Así el que estudia en vida esta artezilla; antes que llegue la muerte, pues no sabes quando llegará; tráela siempre contigo y encomienda a algún amigo o a la persona de quien más te fiares que te acompañe en aquel último tránsito y te ayude al 
exercicio destos documentos. No sólo deves estudiarlos para tu muerte, sino también para favorecer con ellos a tus próximos, $\mathrm{y}$, en particular, a amigos y parientes...» (Antonio de ALVARADO, Arte de bien moriry guía del camino de la muerte, utilizamos la $3^{\mathrm{a}}$ impresión de esta obra, cuya edición original es de 1611, publicada en Yrache: por Nicolás Assiayn, 1615). En este último aspecto de un arte de morir que se aprende también para ser útiles a otros insiste el franciscano Pedro de la FUENTE en otro clásico del género: -que ha de servir«para que cualquiera de los dos Estados (eclesiástico o secular) se ejercite en la obra tan santa como ayudar a bien morir a su hermano» (Breve compendio para ayudar a bien morir, Sevilla: Ioan Gómez de Blas, 1639), y el jesuita Juan Bautista POZA: «Los hombres sabios que pueden ayudar a morir y consolar, y alentar y encaminar a los enfermos son pocos...-por ello- parece necessario enseñar a que ayuden a bien morir los que para este ministerio tuvieron capacidad y tendranla valiendose desta obra todos los que supieren leer, y con la prudencia devida cessaren o prosiguieren con la lectura» (Práctica de ayudar a bien morir, Barcelona: Imp. Sebastián de Cormellas, 1647, p. 2).

(42) Antonio de ALVARADO, op. cit., cap. III, IV y V.

(43) ALVARADO, op. cit., p. 137, Pedro de la FUENTE, op. cit., p. 177 y J.E. NIEREMBERG, Partida a la eternidad y preparación para la muerte, manejamos la edición contenida en I.E. NIEREMBERG, Obras Christianas. Madrid: Domingo García Morrás, 1651, T. I, p. 404v.

(44) Nieremberg, Partida a la eternidad, op. cit., p. 410.

(45) Ibídem.

(46) Ibídem, p. 409v.

(47) FUENTE, op. cit., pp. 177-199.

(48) Ibídem, p. 177.

(49) Fuente, Breve compendio...op. cit., p. 187. También el padre Alvarado advierte que «en muchos casos es bueno hazer en vida el testamento cerrado porque se haze con más libertad», op. cit., p. 138.

(50) P. de la FUENTE, op. cit., p. 180.

(51) J.E. NIERMBERG, Partida a la eternidad..., op. cit., p. $410 \mathrm{v}$.

(52) Ibídem, pp. 180-183.

(53) Antonio de ALVARADO, Arte de Bien Morir, op. cit., p. 143. 
(54) Autores como J. Delumeau, P. Chaunu y Ph. Ariès coinciden en señalar que entre los siglos XIV y XV, la resurrección de la carne, auténtica especificidad de la escatología cristiana, cede protagonismo a una escatología del alma en la que el juicio particular y el purgatorio constituyen dos piezas claves. J. DELUMEAU, La péche et la peur. La culpabilisation en Occident XIIIe-XVIIIe siécles. Paris: Fayard, 1978, pp. 102-105; P. CHAUNU, La mort à Paris 16e, $17 e, 18 e$ siécles. Paris: Fayard, 1978, pp. 243-248 y Ph. ARIES, El hombre ante la muerte. Madrid: Taurus, 1983, p. 502.

(55) «La mayor honra procurada, es causa de mayor afrenta para el defunto, porque no falta quien murmure de las mandas llenas de vanidad y de los entierros pomposos y solemnes», dice el padre Alvarado, op. cit., p. 142. También el padre Nieremberg realiza una breve indicación de que al hacer testamento «dexe toda vanidad y ostentación», Partida a la eternidad, op. cit., p. 409v.

(56) «Orden de los Entierros según el Ritual Romano», en Oficio de Difuntos, orden de los Entierros, los Siete Salmos Penitenciales, trad. por D. Josef RIGUAL. Madrid: Imp. Pedro Marín, 1787, p. 86.

(57) Memorial del cura párroco más antiguo de Cádiz, don Pedro Gómez Bueno al Ayuntamiento, en 26 de octubre de 1801. Archivo Histórico Municipal de Cádiz. Actas Capitulares, n 157, fols. 599-600.

(58) Diccionario Apostólico, trad. al castellano por D. Francisco Mariano NIPHO, t. VIII. Madrid: Imp. Miguel Escribano, 1788, p. 334.

(59) Manifiesto de los curas propios del Sagrario, Archivo Diocesano de Cádiz, Sección Varios, 1795, fol. 1.

(60) Francisca Arnesto de Troya dispone un entierro de medias honras y asistencia de 12 pobres con hachas, «cuya moderada dezencia no puedo escusar por la que corresponde a mi familia, porque a no ser por ésta la limitaría en mucho por mi humildad" (Archivo Histórico Provincial de Cádiz. Sección Protocolos: L. 5077, A. 1725, fol. 300); Marcos Frostal, irlandés, caballero baronet del orden de Irlanda, elige uno de honras enteras «con oficio de las cuatro comunidades que concurren a esta ciudad a los funerables y dobles de sus campanas y todo lo demás que sea correspondiente a el honor de mi persona y empleo, que así es mi voluntad» (Ibídem, L. 2173, A. 1750, fols. 129-134).

(61) Fernando MARTINEZ GIL, Muerte y sociedad en la España de los Austrias. Madrid: Siglo XXI, 1993, p. 422.

(62) J. FAYARD, Los miembros del Consejo de Castilla (1621-1746). Madrid: Siglo XXI, 1982, p. 481. R. GARCIA CARCEL, «Morir a la Barcelona del Barroc», L'Avenç (1985), p. 330. M' J. DE LA PASCUA SANCHEZ, Vivir la muerte en el Cádiz del Setecientos (1675-1801). Cádiz: Fundación Municipal de Cultura, 1990, p. 162). S. GOMEZ NAVARRO, El sentido de la muerte y la 
religiosidad a través de la documentación notarial cordobesa (1790-1814). Análisis y estudio de los testamentos. Granada: Colegio Notarial de Granada, 1985, p. 94.

(63) Durante la segunda mitad del XVIII, en Cádiz, tendrán que prohibirse los entierros sin cruz parroquial, sin cura y con la sola representación de familiares y cofradías, así como todo lo que aparente entierro. En otro lugar hemos seguido la polémica, tal y como se desarrolla en Cádiz ( $M^{a} \mathrm{~J}$. DE LA PASCUA SANCHEZ, «La lucha por el control de las exequias: el síndico personero portavoz del descontento del pueblo gaditano con sus curas párrocos», $L a$ religiosidad popular. Tomo II. Barcelona: Anthropos-Fundación Machado, 1989, pp. 224-243.

(64) Libro I, cap. XXIII. Utilizamos la actualización y traducción de esta obra hecha por el Padre Nieremberg, que sirve de apoyo a una edición realizada en Barcelona, 1845.

(65) Op. cit., p. 58.

(66) Carlos ROSIGNOLI, Verdades eternas, $6^{\circ}$ ed. Barcelona: J. Subirana, 1884, p. 113. 